\title{
Analisis Hukum Waris Islam terhadap Pasal 177 KHI dan SEMA No. 2 Tahun 1994 tentang Besar Bagian Waris Ayah
}

\author{
Refsi Inggranawat*, Shindu Irwansyah \\ Bandung, Indonesia. \\ *refsiinggranawat25@gmail.com, shinduirwansyah@unisba.ac.id
}

Prodi Hukum Keluarga Islam, Fakultas Syariah, Universitas Islam

\begin{abstract}
Q.S. An-Nisa: 11, 12, and 176 are the basis of inheritance law. Q.S.An-Nisa: 11 describes the inheritance of parents when the testator does not leave the child, the mother gets $1 / 3$ part, while the rest of the father. However, KHI brings up 1/3 part for the father when the heir does not leave the child. Against this decree, SEMA was born No. 2 of 1994 as an explanation of the meaning of article $177 \mathrm{KHI}$ so that the sound of article 177 changes to: "father gets $1 / 3$ part if the heir does not leave the child but leaves the husband and mother". Part 1/3 for fathers must be examined whether it is contrary to the Qur'an or not. This research is a qualitative literature study with descriptiveanalysis data processing techniques and legal comparative techniques between classical interpretation, contemporary interpretation with article 177 KHI and SEMA No. 2 of 1994. The results of this study are classical scholars and contemporary scholars agree, in a condition the heir does not leave the child, the father gets the rest. However, there are additions from classical scholars that in the condition of the heir does not leave the child but leaves the husband and mother, the father still gets leftover (ashabah), mother 1/3 of the remainder after being given the husband's share, and husband $1 / 2$. Clause Article 177 KHI and SEMA No. 2 of 1994 became no longer urgent after being reviewed from the Islamic inheritance and after being calculated by gharrawain.
\end{abstract}

Keywords: Classical Interpretation, Contemporary Interpretation, Article 177 KHI, SEMA No. 2 of 1994, Father's Inheritance.

\begin{abstract}
Abstrak. Q.S. An-Nisa: 11, 12, dan 176 adalah dasar hukum waris. Q.S.An-Nisa: 11 menjelaskan waris orangtua ketika pewaris tidak meninggalkan anak, ibu memperoleh $1 / 3$ bagian, sedangkan ayah sisanya. Akan tetapi, KHI memunculkan bagian 1/3 untuk ayah ketika pewaris tidak meninggalkan anak. Terhadap ketetapan tersebut, lahirlah SEMA No. 2 Tahun 1994 sebagai penjelasan tentang pengertian pasal $177 \mathrm{KHI}$ sehingga bunyi pasal 177 berubah menjadi: "ayah mendapat $1 / 3$ bagian apabila pewaris tidak meninggalkan anak tetapi meninggalkan suami dan ibu". Bagian 1/3 untuk ayah harus dikaji apakah bertentangan dengan Al-Qur'an atau tidak. Penelitian ini merupakan penelitian kualitatif yang bersifat kepustakaan dengan teknik pengolahan data deskriptifanalisis dan teknik komparasi hukum antara tafsir klasik, tafsir kontemporer dengan pasal $177 \mathrm{KHI}$ dan SEMA No. 2 Tahun 1994. Hasil dari penelitian ini adalah ulama klasik dan ulama kontemporer sepakat, dalam keadaan pewaris tidak meninggalkan anak, ayah memperoleh sisa. Namun ada tambahan dari ulama klasik bahwa dalam keadaan pewaris tidak meninggalkan anak tetapi meninggalkan suami dan ibu, ayah tetap memperoleh sisa (ashabah), ibu 1/3 dari sisa setelah diberikan bagian suami, dan suami 1/2. Klausul Pasal 177 KHI dan SEMA No. 2 Tahun 1994 menjadi tidak urgent lagi setelah ditinjau dari waris Islam dan setelah dilakukan perhitungan dengan cara gharrawain.
\end{abstract}

Kata Kunci: Tafsir Klasik, Tafsir Kontemporer, Pasal 177 KHI, SEMA No. 2 Tahun 1994, Waris Ayah. 


\section{A. Pendahuluan}

Hukum Islam adalah hukum yang sangat dinamis. Ia dikembangkan sesuai dengan kondisi sosial yang ada, tidak hanya mengatur hubungan manusia dengan Tuhannya saja, tetapi mengatur juga hubungan sesama manusia (muamalah). Di antara hukum yang mengatur tentang hubungan sesama manusia yang ditetapkan Allah Swt. adalah aturan tentang warisan, yaitu harta dan pemilikan yang timbul akibat dari suatu kematian. Syariat Islam telah menetapkan siapa saja yang menjadi ahli waris dan berapa bagiannya, salah satunya adalah mengenai besar bagian waris ayah.

Q.S.An-Nisa: 11 menjelaskan bagian ayah dan ibu ketika pewaris tidak meninggalkan anak di mana ibu memperoleh 1/3 bagian, dan ayah adalah sisanya.

Akan tetapi, keberadaan Kompilasi Hukum Islam sedikit banyaknya telah menimbulkan polemik khususnya di bidang kewarisan, di mana KHI menetapkan ayah sebagai penerima $1 / 3$ ketika pewaris tidak meninggalkan anak. Terhadap ketetapan tersebut, lahirlah SEMA No. 2 Tahun 1994 sebagai penjelasan tentang pengertian pasal 177 KHI sehingga bunyi pasal 177 berubah menjadi: "ayah mendapat $1 / 3$ bagian apabila pewaris tidak meninggalkan anak tetapi meninggalkan suami dan ibu". Munculnya bagian sepertiga untuk ayah tentu saja perlu dilakukan kajian mendalam apakah selaras dengan ketetapan Al-Qur'an atau tidak.

Berdasarkan uraian latar belakang, maka perumusan masalah dalam penelitian ini sebagai berikut: 1) Bagaimana besar bagian waris ayah di dalam ilmu waris menurut pendapat ulama klasik dan ulama kontemporer?; 2) Bagaimana besar bagian waris ayah di dalam Pasal 177 KHI dan SEMA No. 2 Tahun 1994?; Bagaimana tinjauan waris Islam terhadap pasal 177 KHI dan SEMA No. 2 Tahun 1994 tentang besar bagian waris ayah?. Selanjutnya tujuan penelitian ini adalah sebagai berikut: 1) Untuk mengetahui besar bagian waris ayah menurut ilmu waris; 2) Untuk mengetahui besar bagian waris ayah di dalam Pasal 177 KHI dan SEMA No. 2 Tahun 1994; dan 3) Untuk mengetahui tinjauan waris Islam terhadap pasal 177 KHI dan SEMA No. 2 Tahun 1994 tentang besar bagian waris ayah.

\section{B. Metodologi Penelitian}

Penelitian ini merupakan penelitian kualitatif yang bersifat kepustakaan dengan teknik pengolahan data deskriptif-analisis dan teknik komparasi hukum antara tafsir klasik, tafsir kontemporer dengan pasal 177 KHI dan SEMA No. 2 Tahun 1994.

Kata faraid merupakan bentuk jamak dari kata faridah, yang berasal dari kata farada yang artinya adalah ketentuan. Dengan demikian kata faraid atau faridah adalah ketentuanketentuan tentang siapa yang termasuk ahli waris yang berhak mendapatkan warisan, ahli waris yang tidak berhak mendapatkannya, dan berapa bagian masing-masing.

Menurut Soepomo, hukum waris memuat peraturan-peraturan yang mengatur proses meneruskan serta mengoperkan barang-barang harta benda dan barang-barang yang tidak berwujud benda (immateriele goederen) dari suatu angkatan manusia (generatie) kepada turunannya.

Untuk mendapatkan gambaran yang jelas, penulis akan sedikit mengemukakan ayat Al-Qur'an yang dijadikan dasar hukum mengenai kewarisan Islam.

Qur'an Surat An-Nisa ayat 11

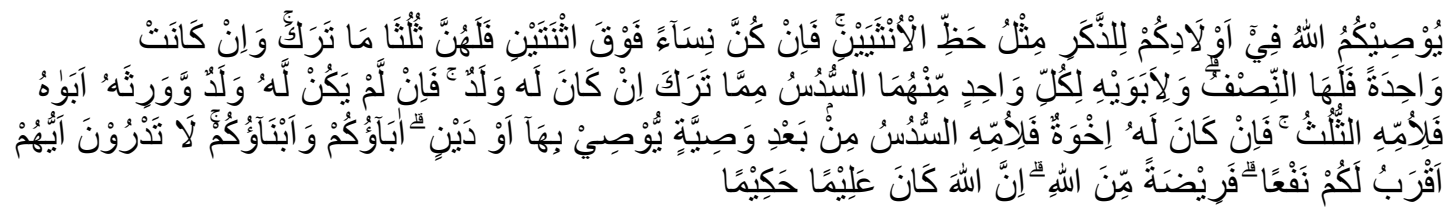

"Allah mensyariatkan (mewajibkan) kepadamu tentang (pembagian warisan untuk) anak-anakmu, (yaitu) bagian seorang anak laki-laki sama dengan bagian dua orang anak perempuan. Dan jika anak itu semuanya perempuan yang jumlahnya lebih dari dua, maka bagian mereka dua pertiga dari harta yang ditinggalkan. Jika dia (anak perempuan) itu seorang 
saja, maka dia memperoleh setengah (harta yang ditinggalkan). Dan untuk kedua ibu-bapak, bagian masing-masing seperenam dari harta yang ditinggalkan, jika dia (yang meninggal) mempunyai anak. Jika dia (yang meninggal) tidak mempunyai anak dan dia diwarisi oleh kedua ibu-bapaknya (saja), maka ibunya mendapat sepertiga. Jika dia (yang meninggal) mempunyai beberapa saudara, maka ibunya mendapat seperenam. (pembagian-pembagian tersebut di atas) setelah (dipenuhi) wasiat yang dibuatnya atau (dan setelah dibayar) utangnya. (Tentang) orang tuamu dan anak-anakmu, kamu tidak mengetahui siapa di antara mereka yang lebih banyak manfaatnya bagimu. Ini adalah ketetapan Allah. Sungguh, Allah Maha Mengetahui, Mahabijaksana." (An-Nisa/4:11).

\section{Hadis Nabi}

Dari Ibn Abbas menurut riwayat Al-Bukhari "Dari Ibnu Abbas dia berkata: Rasulullah bersabda: Berikan bagian-bagian warisan kepada ahli warisnya, selebihnya kepada laki-laki yang dekat."

Di dalam waris Islam, ayah termasuk ahli waris dzul faraidh dan ahli waris ashabah, yakni ashabah binafsihi yaitu ahli waris yang ditarik dari garis ayah yang yang berhak mendapat semua harta atau semua sisa.

Di dalam pasal 174 Kompilasi Hukum Islam, kelompok ahli waris terdiri dari:

1. Menurut hubungan darah: golongan laki-laki terdiri dari ayah, anak laki-laki, saudara laki-laki, paman dan kakek. Golongan perempuan terdiri dari ibu, anak perempuan, saudara perempuan dan nenek.

2. Menurut hubungan perkawinan terdiri dari: duda dan janda.

\section{Hasil Penelitian dan Pembahasan}

Di dalam tafsir Al-Qurthubi, diriwayatkan dari Ikrimah, ia berkata, ia mengutus Ibnu Abbas untuk bertanya kepada Zaid bin Tsabit, tentang seorang wanita yang wafat dan meninggalkan warisannya pada suami dan kedua orang tuanya, ia menjawab, "Bagian suami seperdua, dan bagi ibu 1/3 dan bagi bapak sisa harta warisan." Abu Sulaiman berkata "Pendapat ini dilandasi pada keadilan pembagian warisan jika tidak terdapat nash yang menjelaskan hal tersebut maka dibenarkan ber-istinbath dengan ayat dan hadits, berdasarkan firman Allah Swt,

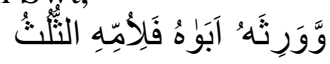

"Jika orang yang meninggal tidak mempunyai anak dan ia diwarisi oleh ibu bapaknya (saja), maka ibunya mendapat $1 / 3$ ", berdasarkan ayat ini jika ibu mendapatkan bagian warisan $1 / 3$ maka sisa harta yaitu $2 / 3$ adalah bagian bapak."

Al-Qurthubi mejelaskan bahwa ibu memperoleh 1/3 dari seluruh harta, itu berlaku pada keadaan pewaris hanya meninggalkan ahli waris ayah dan ibu saja. Pada keadaan demikian, ibu memperoleh 1/3 dari seluruh harta, dan ayah adalah sisanya (ashabah) yaitu 2/3. Sedangkan dalam keadaan ibu mewaris bersama dengan suami atau isteri dan ayah, maka bagian ibu adalah $1 / 3$ dari sisa setelah dibagikan kepada suami sebanyak $1 / 2$, dan untuk ayah adalah sisanya (ashabah).

Abu Ja'far berkata: Makna firman Allah, فَانْ لَّمْ يَكُنْ لََّهْ وَلَدُّ adalah, “Jika yang meninggal dunia itu tidak mempunyai anak laki-laki atau anak perempuan, dan dia hanya diwarisi oleh ibu-bapaknya tanpa ada ahli waris lainnya, فَلأمِِّهِ الثنَّكُ 'maka ibunya mendapat sepertiga'. Allah berfirman, "Oleh karena itu, ibunya mendapatkan sepertiga dari semua harta warisan tersebut". Jika seseorang berkata, "Siapakah selain yang telah disebutkan (ibu), yang berhak mendapat bagian dua pertiga lainnya?" Dijawab, "Ayah". Jika dikatakan, "Mengapa (ayah)?" beliau mengatakan, "(Sebab) ayah adalah keluarga mayit yang paling dekat.

Menurut Wahbah Zuhayli, ketika pewaris tidak meninggalkan anak dan dia hanya diwarisi oleh ibu adn ayahnya saja, maka ibu mendapat $1 / 3$ dan ayah sisanya, karena nash ayah menunjukkan bahwa ayah mengambil bagiannya karena hukum aslinya, harta dibagi untuk mereka berdua. Jika salah seorang sudah mendapatkan bagian, maka yang lainnya mendapatkan sisa.

Menurut Al-Maraghi, bagian waris bagi kedua ibu bapak apabila beserta salah seorang suami-istri, menurut mayoritas pendapat para sahabat bahwa sang suami dari si mayit JRHKI is licensed under Creative Commons Attribution- 
mendapatkan setengah tirkah; dan istri si mayit mendapatkan seperempat bagian dari tirkah, sedangkan sisanya untuk kedua orangtua; yang sepertiga sisa untuk ibunya, sedang sisa seluruhnya untuk ayah.

Besar bagian waris ayah di dalam pasal 177 KHI sangat berbeda dengan Q.S. AnNisa: 11 dan hal tersebut tidak diperkenankan. Sebagaimana dikemukakan oleh Al-Ghazali:

$$
\text { غير و احد فيه والحق لاختلاف مجال يكون فلا لاجتهاد نخالا ليس بالضرورة الزين من علم ما كل }
$$

مثعدد

"Semua yang diketahui secara pasti (qath'i) dalam agama, tidak ada tempat untuk melakukan ijtihad, dan tidak ada pula tempat untuk memperselisihkannya, dan yang benar itu hanya satu tidak ganda."

Terhadap ketetapan tersebut, lahirlah SEMA No. 2 Tahun 1994 sebagai penjelasan tentang pengertian pasal $177 \mathrm{KHI}$ sehingga bunyi pasal 177 berubah menjadi: "Ayah mendapat $1 / 3$ bagian apabila pewaris tidak meninggalkan anak tetapi meninggalkan suami dan ibu."

Penjelasan SEMA No. 2 Tahun 1994 tentang pengertian pasal 177 KHI merupakan kasus gharrawain yang memang menempati kajian tersendiri di dalam Hukum Kewarisan Islam. Akan tetapi, dalam masalah gharrawain pun Umar Ibn Khattab tidak menetapkan ayah sebagai penerima bagian 1/3 melainkan ayah tetap menduduki posisi sebagai ashabah. Sebagaimana pemahaman ulama klasik dalam kasus ini pun sama halnya dengan pemahaman Umar.

Adapun ayah ditetapkan sebagai penerima $1 / 3$ adalah untuk melindungi bagian ayah agar tidak lebih kecil daripada bagian ibu. Agar lebih jelas, penulis akan menyajikan tabel penyelesaian waris ayah yang mungkin dilakukan, sebagai berikut:

Tabel. 1 Penyelesaian waris menurut Q.S. An-Nisa: 11 dan 12

\begin{tabular}{|c|c|c|}
\hline Ahli Waris & Bagian & Asal Masalah (6) \\
\hline Suami & $1 / 2 \times$ AM (6) & 3 \\
\hline Ibu & $1 / 3 \times$ AM (6) & 2 \\
\hline Ayah & Ashabah & 1 \\
\hline & & $6 / 6$ \\
\hline
\end{tabular}

Dari tabel tersebut kita melihat bahwa bagian ayah lebih kecil dari bagian ibu. Hal ini bertentangan dengan lidzakari mitslu hadzil untsayain yang merupakan prinsip kewarisan Islam.

Untuk mengatasi masalah ini, Umar memahami bahwa yang diterima ibu adalah $1 / 3$ sisa setelah diberikan kepada suami, bukan 1/3 dari seluruh harta. Maka penyelesain menurut cara gharrawain adalah sebagai berikut:

Tabel 2. Penyelesaian waris menurut cara gharrawain

\begin{tabular}{|c|c|c|}
\hline Ahli Waris & Bagian & Asal Masalah (6) \\
\hline Suami & $1 / 2 \times$ AM (6) & $3($ Sisa=3) \\
\hline Ibu & $1 / 3$ sisa $\times($ sisa=3) & 2 \\
\hline Ayah & Ashabah & $6 / 6$ \\
\hline
\end{tabular}


Penyelesaian dengan cara gharrawain ini telah sesuai dengan prinsip lidzdzakari mitslu hadzil untsayain (bagian seorang laki-laki sama dengan bagian dua orang perempuan), di mana bagian ayah lebih besar dari bagian ibu. Meskipun bagian ibu berubah dari 1/3 menjadi 1/6. Alasan yang dikemukakan untuk mentakwilkan $1 / 3$ bagian ibu menjadi $1 / 3$ sisa adalah untuk menghindari agar bagian yang diterima oleh ibu tidak lebih besar dari bagian yang diterima ayah.

Adapun ketentuan ayah berdasarkan penjelasan SEMA No. 2 Tahun 1994 adalah sebagai berikut:

Tabel 3. Penyelesaian waris Berdasarkan SEMA No. 2 Tahun 1994

\begin{tabular}{|c|c|c|}
\hline Ahli Waris & Bagian & Asal Masalah (6) \\
\hline Suami & $1 / 2 \times$ AM (6) & 3 (Sisa=3) \\
\hline Ibu & $1 / 3$ sisa x (sisa=3) & 2 \\
\hline Ayah & $1 / 3 \times$ AM (6) & $6 / 6$ \\
\hline
\end{tabular}

Bila kita perhatikan tabel 3, Penyebutan ayah sebagai ahli waris penerima bagian 1/3 di dalam pasal 177 KHI dan SEMA No. 2 Tahun 1994 merupakan suatu bentuk ijtihad baru untuk melindungi bagian ayah dengan memberikan bagian pasti kepadanya yaitu dengan memunculkan nilai dari ashabah yakni 1/3. Dengan demikian, besar bagian waris ayah di dalam pasal 177 KHI dan SEMA No. 2 Tahun 1994 sama dengan hukum waris Islam yang mengambil pendapatnya Imam al-Qurthubi dalam kitab tafsirnya yang berjudul Al-Jami' Li Ahkam Al-Qur'an.

\section{Kesimpulan}

Berdasarkan pembahasan dalam penelitian ini, dapat diambil kesimpulan sebagai berikut:

1. Besar bagian waris ayah di dalam ilmu waris Islam yang mengambil pendapat ulama klasik dan ulama kontemporer bahwa dalam keadaan pewaris tidak meninggalkan anak, ayah memperoleh bagian sisa atau ashabah. Namun ada tambahan dari ulama klasik bahwa dalam keadaan pewaris tidak meninggalkan anak tetapi meninggalkan suami dan ibu, maka ayah tetap memperoleh ashabah atau 1/3.

2. Besar bagian waris ayah di dalam Pasal $177 \mathrm{KHI}$, ayah memperoleh $1 / 3$ ketika pewaris tidak meninggalkan anak. Terhadap pasal tersebut diberlakukan SEMA No. 2 Tahun 1994 tentang Pengertian Pasal 177 KHI, sehingga bagian ayah adalah 1/3 ketika pewaris tidak meninggalkan anak, tetapi meninggalkan suami dan ibu.

3. Besar bagian waris ayah di dalam Pasal 177 KHI dan SEMA No. 2 Tahun 1994 sama dengan hukum waris Islam yang mengambil pendapatnya Al-Qurthubi di dalam kitab tafsirnya yang berjudul Al-Jami’ Li Ahkam Al-Qur'an.

\section{Daftar Pustaka}

[1] Al-Asqalani, I. H. (1995). Bulughul Maram. Surabaya: Mutiara Ilmu.

[2] Al-Maraghi, A. M. (1974). Tafsir Al-Maraghi Jilid 4. Mesir: Mushthafa Al-Babi AlHalabi.

[3] Al-Qurthubi. (2006). Tafsir Al-Qurthubi Jilid 5. Beirut: Al-Resalah.

[4] Al-Zuhayli, W. (2009). Tafsir Al-Munir Jilid 2. Damaskus: Dar Al-Fikr.

[5] Ath-Thabari, A. J. ( 2001). Tafsir Jami' al-Bayan 'An Ta'wil Ay al-Qur'an. Thob'atul Ula.

[6] Khisni, A. (2011). Ijtihad Hakim Peradilan Agama Bidang Hukum Kewarisan dan 
68 | Refsi Inggranawat, et al.

Kontribusinya Terhadap Hukum Nasional. Jurnal Hukum No, Edisi Khusus, Vol. 18, 157.

[7] Sa'dan, S. (2017). Ijtihad terhadap Dalil Qath'i dalam Kajian Hukum Islam. Samarah: Jurnal Hukum Keluarga dan Hukum Islam Vol. 1, No. 2, 482.

[8] Suparman, E. (2018). Hukum Waris Indonesia Dalam Perspektif Islam, Adat dan BW, Cet. Kelima. Bandung: PT. Refika Aditama. 